\title{
A new model of respiration in blastoid (Echinodermata) hydrospires based on computational fluid dynamic simulations of virtual 3D models
}

\author{
Johnny A. Waters, ${ }^{1}$ Lyndsie E. White, ${ }^{1}$ Colin D. Sumrall, ${ }^{2}$ and Bonnie K. Nguyen ${ }^{1}$ \\ ${ }^{1}$ Department of Geology, Appalachian State University, Boone, North Carolina, 28608, USA 〈watersja@appstate.edu〉, \\ 〈white.lyndsie@gmail.com〉,〈bonner.ngu@gmail.com〉 \\ ${ }^{2}$ Department of Earth and Planetary Sciences, 1412 Circle Dr., 306 EPS, University of Tennessee, Knoxville, Tennessee, 37996-1410, USA \\ 〈csumrall@utk.edu $\rangle$
}

\begin{abstract}
Hydrospires are internal structures in blastoids that primarily served a respiratory function. Historically, hydrospires have been modeled as passive-flow respiratory structures with a vertical orientation. This project constructed virtual 3D models of blastoids from legacy acetate peel collections at the Naturalis Museum in the Netherlands. Computational fluid dynamic (CFD) simulations of the blastoid models reconstructed in living position indicated that hydrospires likely were oriented horizontally when the blastoid was in feeding mode in current velocities $>0.5 \mathrm{~cm} / \mathrm{s}$ to $10 \mathrm{~cm} / \mathrm{s}$. In this range of current velocities, passive water flow through the hydrospires did not produce conditions optimized for efficient gas exchange. However, optimal water flow through the hydrospires could be achieved if the excurrent velocity of water exiting the hydrospire through the spiracle was approximately one-half the velocity of ambient environmental currents. Maintaining such a ratio in the dynamic current systems in which blastoids lived suggests that cilia-driven active water flow through the hydrospires is a better model for optimizing respiratory effectiveness.
\end{abstract}

\section{Introduction}

Blastoids are the longest lived and most diverse members of the Blastozoa, a major component of the Great Ordovician Biodiversification Event (Sprinkle and Guensburg, 2004). They are important components of evolving Paleozoic echinoderm communities, which experienced changing paleogeography, major mass extinction events, and changing paleoclimates.

Recent studies by Sumrall (2010), Sumrall and Waters (2012), and Kammer et al. (2014) demonstrate that external morphology and homology of fossil stemmed echinoderms can be reconciled across clades and used to score characters for phylogenetic inference. Like many stemmed echinoderms, most of the phylogenetic information used to infer blastoid evolution is derived from the globular to bud-shaped theca that houses the visceral cavity and respiratory structures (hydrospires). This largely reflects a taphonomic bias because skeletal elements in the thecae of blastoids are tightly sutured into a strong taphonomic module that is easily preserved (Brett et al., 1997). Consequently, thecae are typically very well preserved in three dimensions and often include preservation of the internal structures (Dexter et al., 2009; Schmidtling and Marshall, 2010; Bauer et al., 2015, 2017). Blastoids are also significant components of analyses inferring the phylogenetic placement of Crinoidea within the context of Paleozoic stemmed echinoderms (Kammer et al., 2014). Thus, testing hypotheses of the phylogeny of extant crinoid clades requires a firm understanding of the phylogeny of extinct clades, particularly the Blastozoa.
The traditional classification in the Treatise of Invertebrate Paleontology (Fay, 1967) places blastoids into two orders: Fissiculata, characterized by hydrospires that open to the ambient seawater via slits along the edges of the ambulacral system, and Spiraculata, characterized by hydrospires that communicate with the ambient seawater through pores along the edges of the ambulacral side plates and spiracle exit pores on the thecal summit near the mouth. Blastoid respiratory structures (hydrospires) are often preserved because they are lightly calcified (Beaver, 1996). These folds can be readily seen in thin sections and acetate peels and have been shown to vary across blastoid groups (Fay, 1967).

Waters and Horowitz (1993) concluded that the spiraculate condition is an evolutionary grade rather than a clade. They suggested that fissiculate blastoids evolved into spiraculates in at least five separate lineages during the Silurian and Devonian. Four origins were given ordinal status on the basis of thecal shape and spiracular, deltoidal, and ambulacral morphologies. A fifth order was recognized but remains unnamed pending taxonomic revision of the taxa involved.

Traditionally, hydrospire morphology was examined from a single transverse cross section made at the radial/deltoid suture (Fay, 1967). With this limited analysis, hydrospire shape and number could be accessed but little information could be determined concerning three-dimensional morphology, function, and how the structures formed spiracles. More detailed analyses (Breimer and Macurda, 1972) used serial acetate peels, but threedimensional reconstructions were not generated because of the limitations of the technology at the time. New advances in virtual 
paleontology now allow for the reconstruction of hydrospires in three dimensions and the testing of fluid flow models through the respiratory system (Bauer et al., 2015, 2017).

\section{Imaging the interior of blastoid thecae}

Virtual paleontology studies fossils through digital visualization of the three-dimensional morphology (Sutton et al., 2013). The raw data for virtual 3D reconstructions of internal morphologies in fossils usually involve tomographs, a series of two-dimensional parallel slices, of a specimen that are gathered by either destructive or nondestructive methodologies (Cunningham et al., 2014). Historically, tomographic data consisted of thin sections or acetate peels (Sollas, 1904; Stensio, 1927; Muir-Wood, 1934; Stewart and Taylor, 1965) collected through destructive techniques such as serial grinding, sawing, or slicing. Until the advent of high-speed computing and 3D reconstruction software, individual tomographic slices provided the morphologic information required to taxonomic delineation. These tomographic slices were often coarsely and unequally spaced. Three-dimensional reconstructions were rare, time consuming, and accomplished via the construction of physical models (Sollas, 1904; Jarvik, 1954). Jefferies and Lewis (1973) and Schmidtling and Marshall (2010) offer examples of echinoderm reconstructions using serial sections. Acetate peels were widely used to interpret the internal morphology of brachiopods (e.g., Copper, 1967; Posenato, 1998; SchemmGregory, 2014), corals (e.g., Wang, 2013), and many other fossil groups, including blastoids (Breimer and Macurda, 1972). Modern nondestructive methodologies include X-ray tomography, magnetic resonance imaging, and neutron tomography (Cunningham et al., 2014).

Modern techniques produce high-resolution 2D images that can be reconstructed as three-dimensional computer models using appropriate visualization software. X-ray tomography is capable of micron-scale resolution, and synchrotron facilities are increasingly available; hence, the technique is commonly used in paleontology. X-ray tomography works well when the internal structures being imaged and the material filling the voids have significant density contrast (Abel et al., 2012) or when specimens are preserved as molds (Rahman et al., 2015a). These techniques are not as successful in specimens showing little density contrast between internal structures and the void filling because materials with similar densities attenuate X-rays to similar degrees, and so are not clearly differentiated in the resulting slice images. This situation commonly occurs in blastoids as well as other fossil echinoderm clades (Waters et al., 2015).

Although digital techniques, such as synchrotron imaging, are clearly preferable when available and can produce spectacular results (Rahman et al., 2015b), acetate peels provide important morphological data critical to studies of blastoid phylogeny that are currently unavailable using nondestructive imaging technology, particularly where there is low-density contrast within specimens. Even in these cases, the boundaries separating echinoderm plate material and hydrospires from spary and micritic thecal fill are clearly defined in acetate peels because echinoderm plates are constructed of microporous stereom. Consequently, we have concluded that legacy collections of acetate peels remain a viable data source for visualizing the internal structures of blastoids.

\section{Previous studies of water flow through blastoid hydrospires}

Hydrospires are lightly calcified internal infoldings of the deltoid and radial plates of blastoids typically formed adjacent to the ambulacra. They can occur singly or in groups from two to 10 and are presumed to have had a respiratory function; they may be reduced in number or absent in the anal (CD) interray (Breimer and Macurda, 1972). Hydrospires have two closely spaced walls forming the hydrospire fold with a bulbous termination called the hydrospire tube (Beaver et al., 1967) or hydrospire bulb (Schmidtling and Marshall, 2010). In spiraculates, hydrospires are connected by hydrospire pores and canals located along the edges of the ambulacra and spiracles at the summit of the theca. Bauer et al., (2017) discusses hydrospire morphology, the history of study, and phylogenetic implications in greater detail.

Schmidtling and Marshall (2010) were the first authors to consider the flow of water through the hydrospire system by reconstructing a high-resolution, three-dimensional hydrospire model of the blastoid Pentremites rusticus Hambach, 1903 using serial sections. Drawing on their detailed morphological analysis, they proposed the following flow of water through the system. Water enters the hydrospire through the hydrospire pores and passes through the pore canal to reach the hydrospire fold. No significant gas exchange happens in the hydrospire pore or pore canal. Water then enters the hydrospire fold, where gas exchange occurs. Oxygen-depleted water exits the hydrospire system via the hydrospire tube and spiracles.

Using the principle of continuity, Schmidtling and Marshall (2010) proposed a model of passive water flow through the hydrospire system. Water velocity would slow dramatically as water entered the hydrospire folds from the pores and pore canals. Because the hydrospires of Pentremites rusticus expanded in size adorally, water maintained a more or less constant velocity relative to incurrent velocity and exited the spiracle at a similar velocity unless the spiracular cover plates were used to reduce the size of the spiracular opening.

Using the observations and calculations summarized in the preceding, Schmidtling and Marshall (2010) proposed a residence time of water in the hydrospires of $\sim 385$ seconds. Their hypothesized water flow in Pentremites rusticus is on the same order of magnitude as modern invertebrates with passive fluid flow but on the order of 1,000 times smaller than flow rates from organisms employing active ciliary-driven water flow.

Huynh et al. (2015) expanded the observations and hypotheses of Schmidtling and Marshall (2010) by constructing a highly enlarged (72x) physical 3D model of a partial hydrospire and conducting fluid flow experiments. The results of their experiments seemed to confirm the hypothesis of Schmidtling and Marshall (2010) that water entering the hydrospire pores flowed parallel to the pores while in the hydrospire fold without mixing with water entering adjacent pores. These water "units" did not mix until they reached the hydrospire bulb and began their exit from the system. 


\section{Materials and methods}

The Naturalis Biodiversity Center in Leiden, Netherlands, houses a legacy collection of acetate peels of blastoids produced in the late 1960s (Breimer and van Egmond, 1968). A typical specimen in this collection was serially sectioned perpendicular to the polar axis producing between 50 and 100 acetate peels. Etched and unetched peels were produced at each interval. Although the specimens were destroyed during the sectioning process, the peels are in pristine condition considering their age and remain an important source of detailed information about the internal morphology of blastoids. Eventually, the peels will be digitized and available online as part of the Naturalis Biodiversity Center's digitization initiative. Using individual acetate peels from this collection, Breimer and Macurda (1972) proposed major evolutionary trends in fissiculate blastoids. Morphologic information from the majority of the peels has never been published. Peels from representatives of 40 genera were scanned individually at 3,600 dpi with 8-bit grayscale using a Braun slide scanner with the goal of using the digitized peels to virtually recreate the internal and external blastoid morphology.

Many 3D reconstruction software alternatives are available to transform tomographic data sets into 3D reconstructions (Cunningham et al., 2014). SPIERS (Serial Palaeontological Image Editing and Rendering System) is a widely used, freely available package of three programs for the reconstruction and visualization of tomographic data sets (http://www.spierssoftware.org). Using SPIERS to construct 3D visualizations from serial sections and acetate peels is challenging if the serial sections are not equally spaced and if fiduciary markings to aid alignment are not present. Although most modern data sets from serial sections do not suffer these problems, many legacy data sets, including ours, do have these issues.

To reconstruct blastoids from the acetate peels, we developed a visualization workflow (Fig. 1) based on Rhinoceros software, a NURBS- (nonuniform rational basis spline) based 3D computer graphics and CAD (computer-aided design) software that produces mathematically precise representations of curves and freeform surfaces. Because Rhinoceros is widely used in rapid prototyping, computer-aided design and manufacturing, and graphic design, it easily interfaces with a variety of other 3D visualization software packages and 3D printers. Rhinoceros makes no assumptions about vertical spacing of tomographic slices, and the user can interactively edit the vertical spacing as the model is reconstructed.

The acetate peels of the blastoids lack homologous points of reference and must be manually realigned using Photoshop. Once peels are digitized and registered, the specimen outline is clipped from the background and stacked into layers to virtually recreate the blastoid that had been destroyed through serial sectioning. Morphologic characters of interest from individual digitized peels can be characterized as regions of interest (ROI) and are segmented on separate layers using Photoshop. The layers are exported into Illustrator and converted to an AutoCAD drawing file. The ROIs are lofted into 3D models using Rhino software and can be viewed electronically or converted to physical models by $3 \mathrm{D}$ printing. The internal anatomy of a specimen of Pentremites godoni (DeFrance, 1819) (Fig. 1) was reconstructed from 95 acetate peels using the workflow described in the preceding. A model of the internal anatomy of Monoschizoblastus rofei (Etheridge and Carpenter, 1886) (Fig. 2) was similarly reconstructed from 76 peels. The hydrospire model of Monoschizoblastus rofei was prepared for fluid flow simulation by hollowing (Fig. 3.2) and adding hydrospire pores. We added 30 hydrospire pores to each hydrospire in accordance with our observations of a similarly sized specimen of Monoschizoblastus rofei in our collections. The length of the pore canals was based on the thickness of the thecal plates in the original sectioned specimen.

An enhanced model of Monoschizoblasus rofei with stem, theca with hydrospires, and brachiolar filtration fan (Fig. 4) was produced in Rhinoceros by adding the stem and brachioles to the 3D model produced from the acetate peels. The orientation of the stem and filtration fan followed the Type 1 feeding model of Breimer and Macurda (1972).

\section{Computational fluid dynamic simulations of fluid flow through blastoid hydrospires}

Our initial goal was to virtually re-create the experiment by Huynh et al. (2015) and test the hypotheses of water flow through hydrospires developed by Schmidtling and Marshall (2010) and Huynh et al. (2015). We used the model of Monoschizoblastus rofei because it has the simplest configuration of hydrospires seen in blastoids: 10 single hydrospires (Fig. 2) each emptying into a single spiracle with the exception of the anal interray hydrospires, which empty into an anispiracle (Fig. 3.1).

Fluid flow through the hydrospire model of Monoschizoblastus rofe $i$ was calculated using the computational fluid dynamics (CFD) module of Solidworks, a widely available computer-aided design (CAD) and computer-aided engineering (CAE) software package. A life-size (thecal length $10 \mathrm{~mm}$ ) hydrospire model was placed into the CFD domain and simulated on the basis of $~ 931,000$ fluid cells (Fig. 3.4-3.7). The hydrospire model was surrounded by a fluid domain of rectangular solid shape. The distance between the inlet and the hydrospire model was about two times the thecal length; between the model and the outlet was three times the thecal length. Simulations using larger computational domains did not result in significant changes of the observed flow patterns. Mesh refinement showed good convergence; an increase in cell number did not result in significant changes of velocities. The fluid domain used seawater parameters (average density $=1,026.021 \mathrm{~kg} / \mathrm{m}^{3}$, dynamic viscosity $=0.00122 \mathrm{~Pa} \cdot \mathrm{s}$ ), with unidirectional flow from the external side of the hydrospire (the side having the hydrospire pores). Initial water velocity into the hydrospire pore was set at $0.6 \times 10^{-3} \mathrm{~m} / \mathrm{s}$ as defined by Huynh et al. (2015) from estimates by Paul (1978) with turbulence set at $4 \%$. The fluid domain had free-slip wall conditions to best approximate an open-water domain. We also used free-slip conditions in the internal walls of the hydrospire as a default condition. The Reynolds number for the hydrospire measured at the hydrospire pore is 0.787 , similar to results reported by Huynh et al. (2015), who concluded that a laminar flow regime existed inside blastoid hydrospires.

Water entering the hydrospire fold flows more or less horizontally at a significantly reduced velocity until it reaches 


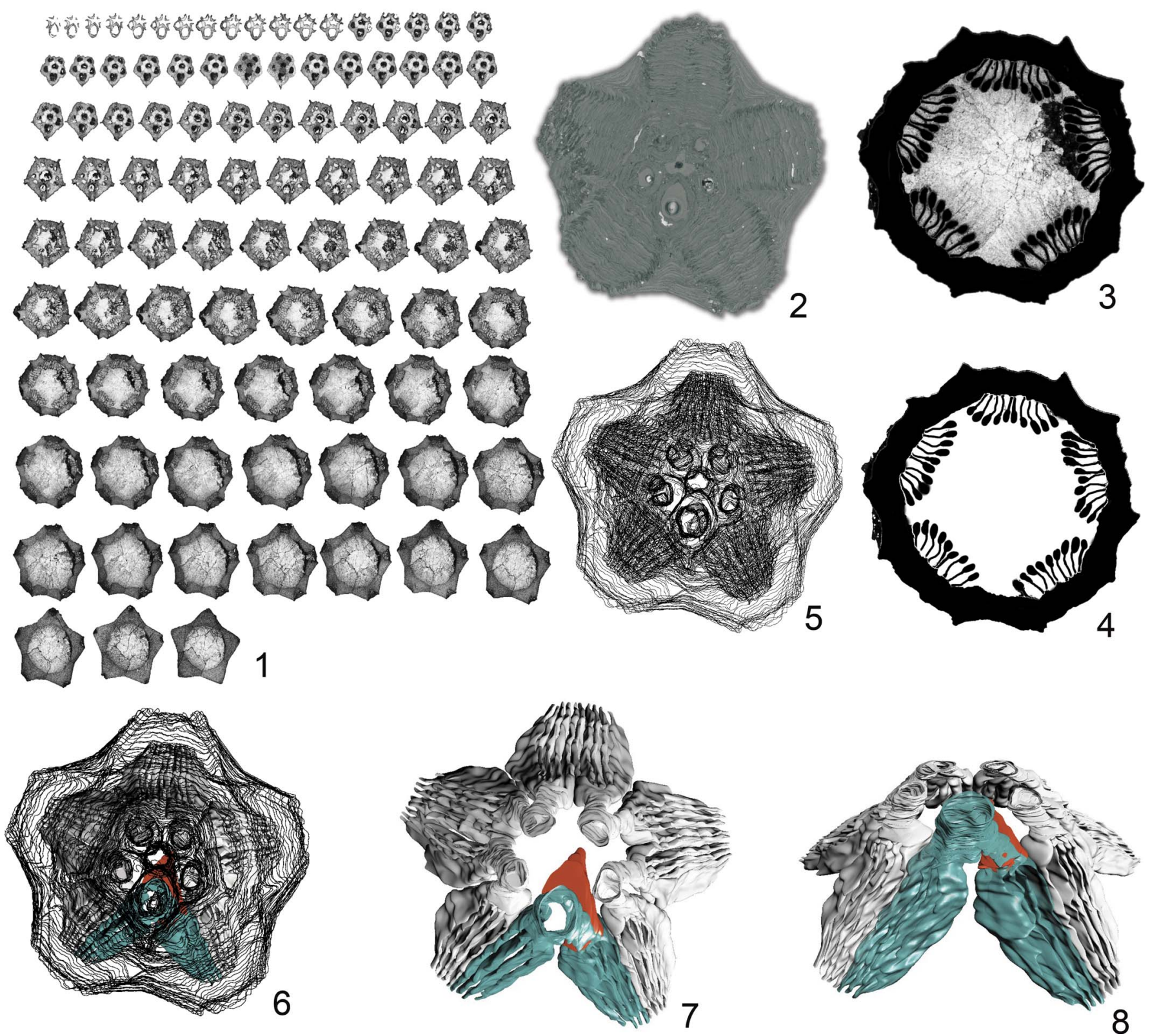

Figure 1. Reconstruction of Pentremites godoni from 95 acetate peels: (1) digitized acetate peels; (2) digitized peels registered, specimen outline clipped from background and stacked to virtually recreate the blastoid that had been destroyed through serially sectioning; (3) regions of interest (ROI), such as the thecal plates and hydrospires, segmented on individual digitized peels using Photoshop; $(\mathbf{4}, \mathbf{5})$ digitized peels exported into Illustrator and converted into an Auto-CAD drawing file; (6-8) ROIs lofted into 3D models using Rhino software that can be viewed electronically or converted to physical models by 3D printing. In this example, the hydrospires (one hydrospire set in green) and gonad (orange) of Pentremites godoni can be visualized. Not only can these internal morphologic structures now be viewed accurately, in the case of the hydrospires, which are presumed respiratory structures, they provide quantitative data on surface area and volume and can be used as input into fluid flow simulations.

the hydrospire tube where water flow is vertical with increasing speed adorally. We ran two different versions of the model, one with an unrestricted spiracle (Fig. 3.4) and one with the spiracle partially restricted as it is in actual specimens (Fig. 3.5-3.6). Restricting the spiracular opening increased the exit velocity as one would expect given the principle of continuity.

With these simulations, we can support the basic hypotheses of Huynh et al. (2015) and Schmidtling and Marshall (2010) with respect to water flow through the hydrospires. Because water flow in the hydrospire fold is significantly reduced, residence time would increase, supporting the hypothesis that gas exchange occurred in the fold. The horizontal flow of water in the hydrospire fold is important because it reduced respiratory leakage as discussed by Huynh et al. (2015). The hypothesis that the hydrospire tube acts as a chimney removing wastewater is supported by adoral flow of increasing velocity toward the spiracle. Comparisons with many of the other specific results discussed by Schmidtling and Marshall (2010) are not possible at this stage because the hydrospire system in Monoschizoblasus rofei is different from that seen in Pentremites rusticus (Figs. 1.7, 1.8, 2), which was only partially reconstructed. 


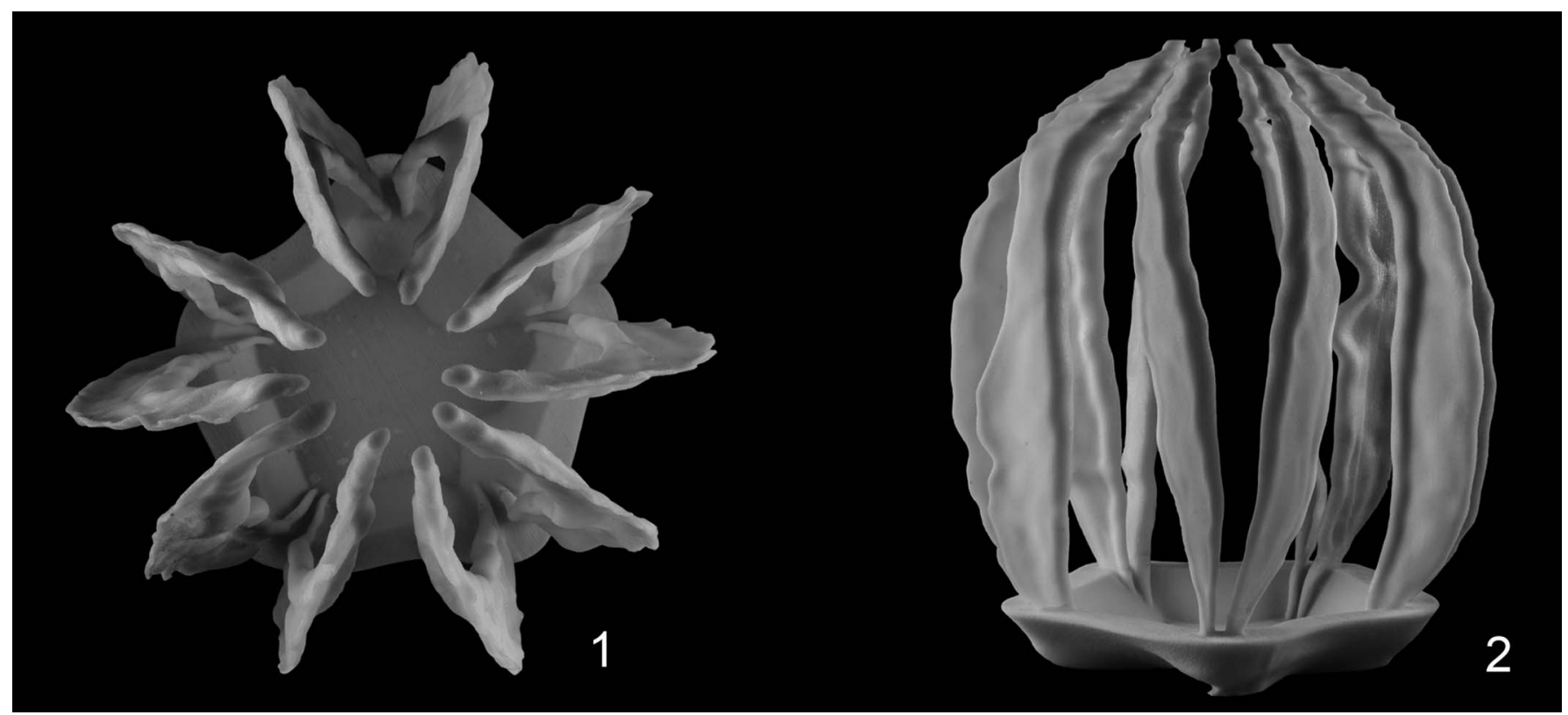

Figure 2. The ten hydrospires of Monoschizoblastus rofei have been segmented from 76 acetate peels using Rhino 3D reconstruction software and are shown as photographs of physical 3D models in (1) oral and (2) lateral views.

Although our CFD results were similar to those from Huynh et al. (2015) and Schmidtling and Marshall (2010), these previous studies have a fundamental flaw: hydrospire flow was modeled with the hydrospires oriented vertically in life, which they are not according to the reconstructions of Breimer and Macurda (1972). Figure 4 shows our reconstruction of Monoschizoblasus rofei based on the hypothesis (Breimer and Macurda, 1972) that Type 1 stemmed blastoids were oriented horizontally with a parabolic brachiolar filtration fan in a current flowing toward the oral surface. Breimer and Macurda (1972) recognized other feeding strategies in blastoids, but Type 1 feeding was the most common mode of feeding in blastoids. According to CFD studies by Dynowski (2014), modern crinoids are oriented in this manner in water currents from $0.5 \mathrm{~cm} / \mathrm{s}$ to $50 \mathrm{~cm} / \mathrm{s}$. They have a vertical orientation only in current velocities $<0.5 \mathrm{~cm} / \mathrm{s}$. Dynowski et al. (2016) illustrated similar feeding orientations for the fossil crinoid Encrinus liliiformis Lamarck, 1801.

Because blastoid feeding is modeled on modern stemmed crinoids, either we must assume that blastoids only lived in very low energy current conditions with the theca oriented vertically or we must consider a more complex model of blastoid ecology and hydrospire function. Given the variety of sediments in which blastoids are found from the encrinites of the Burlington Limestone to the shaly carbonate mudstones of the Chesterian of the midcontinent of the United States, we can make a reasonable case that blastoids lived in a variety of depositional settings with dynamically variable current velocities.

The model of Monoschizoblasus rofei with stem, theca with hydrospires, and brachiolar filtration fan (Fig. 4) was imported into a CFD domain to visualize simultaneous water flow around the theca through the filtration fan and internally into the hydrospires under varying external current velocities. Preliminary results from CFD modeling of blastoid feeding (Nguyen et al., 2015) using this and other models suggest that the blastoids were optimized for current conditions of $2 \mathrm{~cm} / \mathrm{s}$ to $10 \mathrm{~cm} / \mathrm{s}$. Fluid flow was calculated in the (CFD) module of Solidworks. The reconstruction was placed into the CFD domain at life size (thecal length $10 \mathrm{~mm}$, stem length $10 \mathrm{~cm}$, diameter of the filtration fan $30 \mathrm{~mm}$ ). The CFD simulation evaluated the model on the basis of 4,834,580 fluid cells. The model was surrounded by a fluid domain of rectangular solid shape. The distance between the inlet and the model was about two times the length of the reconstruction; between the model and the outlet was three times the reconstruction length. Simulations using larger computational domains did not result in significant changes of the observed flow patterns. Mesh refinement showed good convergence, and an increase in cell number did not result in significant changes of velocities. The fluid domain used seawater parameters (average density $=1,026.021$ $\mathrm{kg} / \mathrm{m}^{3}$, dynamic viscosity $=0.00122 \mathrm{~Pa} \cdot \mathrm{s}$ ), with unidirectional flow from the aboral to the oral side of the reconstruction. Initial external water velocity was $10 \mathrm{~cm} / \mathrm{s}$ with turbulence set at $4 \%$. The fluid domain had free-slip wall conditions to best approximate an open-water domain. The Reynolds number for the model using thecal length of $10 \mathrm{~mm}$ as the hydraulic diameter is 84.1 . If the hydraulic diameter of the model is increased to $30 \mathrm{~mm}$ reflecting the width of the theca and the filtration fan, the Reynolds number increases to 252 , indicating laminar flow in both scenarios.

In this simulation, the velocity of water entering the hydrospire pores was not specified. Rather, we set the initial velocity of the water current entering the fluid domain at $10 \mathrm{~cm} / \mathrm{s}$

Figure 3. Hydrospires of Monoschizoblastus rofei: (1) hydrospires visualized in Photoshop as Rhino segmentations (in blue) within a highly desaturated composite; $(2,3)$ hydrospire reconstruction converted to model for CFD simulation by adding hydrospire pores and canals and hollowing the resulting model; (4) CFD simulation with a completely open spiracle; (5) simulation with a partially closed spiracle; (6) enlarged view of spiracle; (7) velocity scale for the fluid flow simulations. 

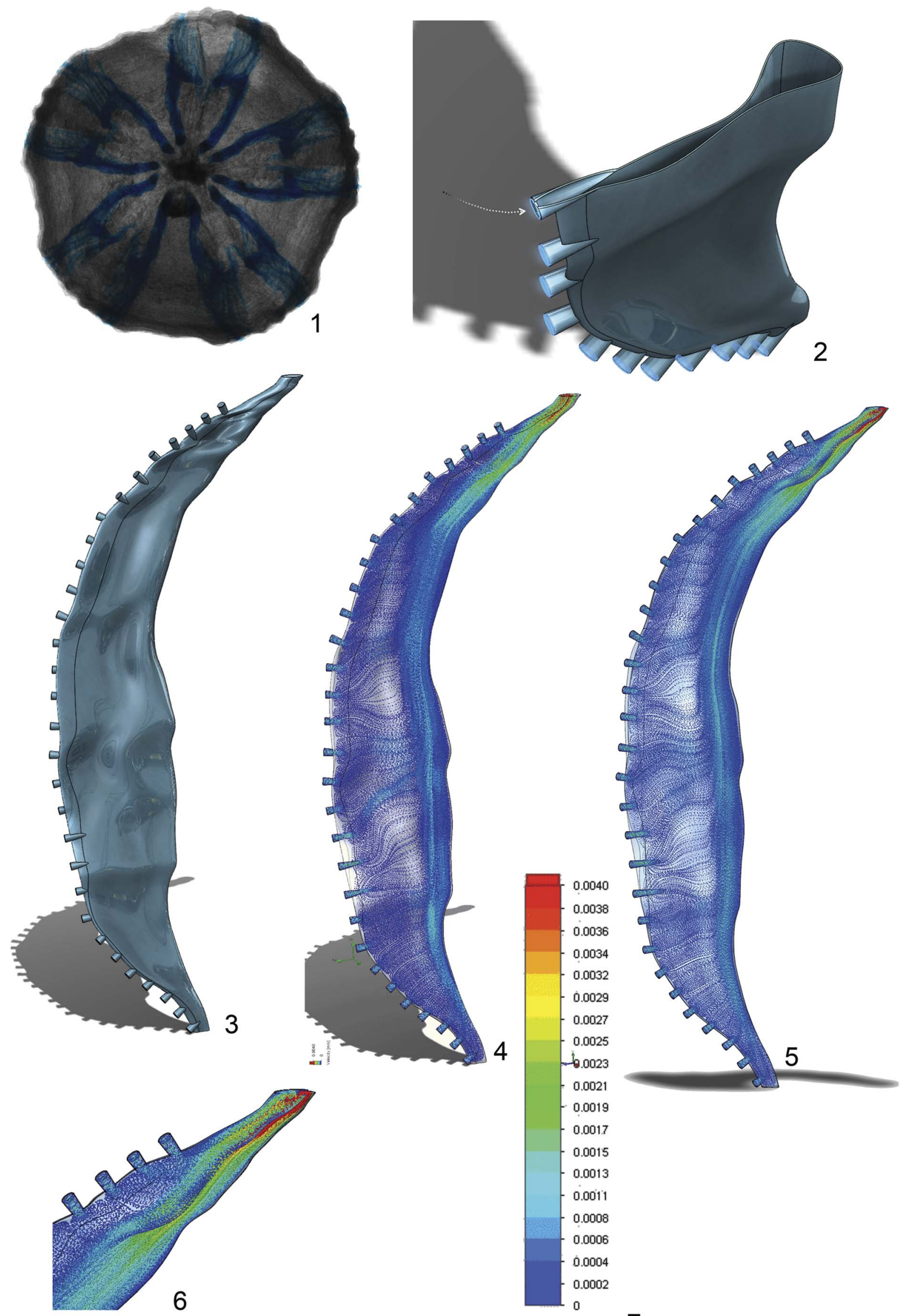

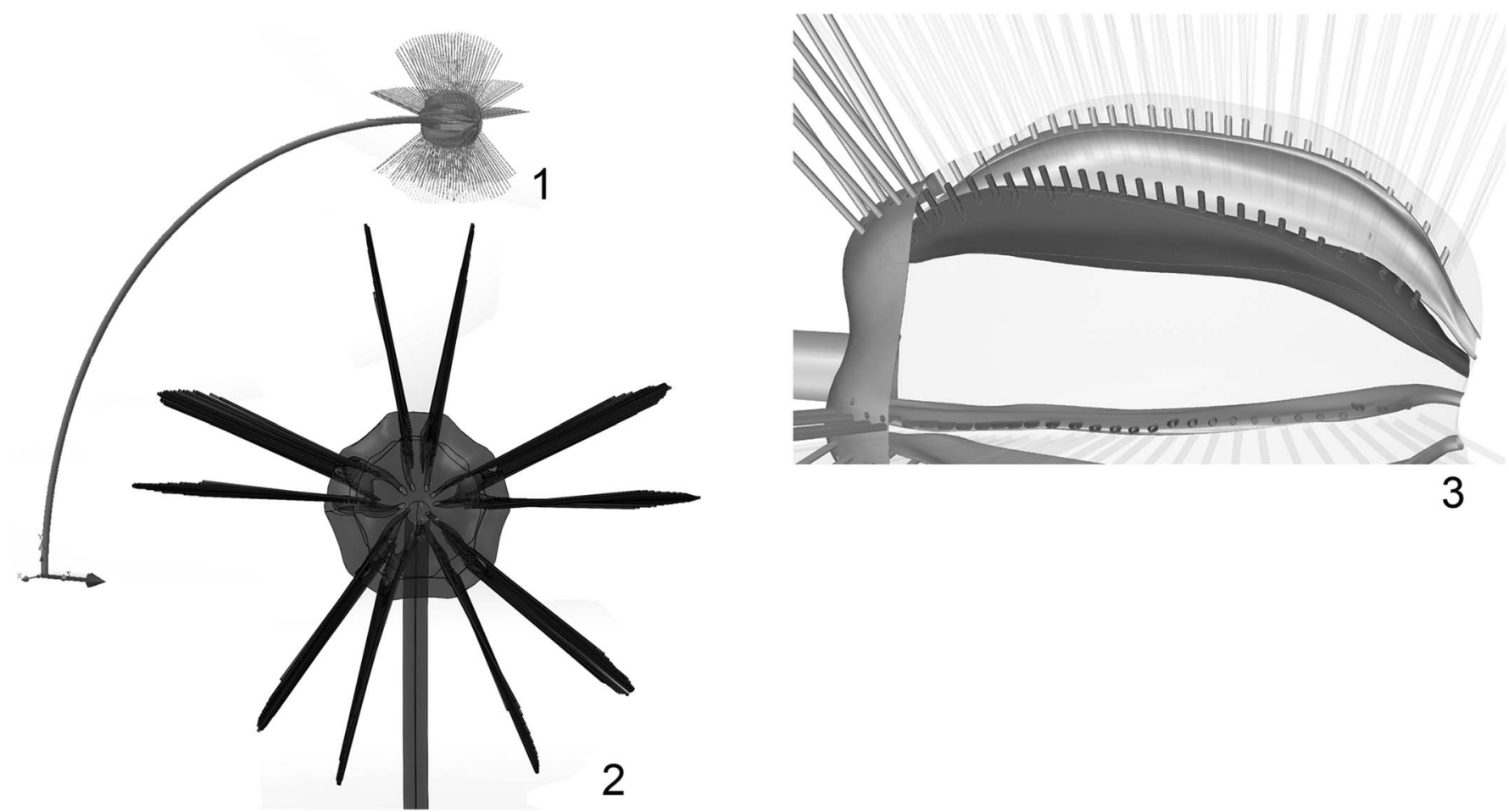

Figure 4. Models of Monoschizoblastus rofei: (1) reconstruction of Monoschizoblastus rofei in feeding position with stem bent into the current with a brachiolar filtration fan; (2) semitransparent oral view of Monoschizoblastus rofei showing the hydrospires leading into spiracles in relation to brachioles; (3) lateral cut view showing the hydrospires, hydrospire pores, and pore canals.

and allowed the hydrospire pores and spiracles to act as openings under ambient environmental conditions. The simulation produced unexpected results with respect to fluid flow through the hydrospire. Because the hydrospire pores are very small openings, the majority of the water flowed around the theca and filtration fan as expected. Water entered the hydrospire pores at varying velocities because water flow is predominantly parallel to pore opening rather than largely perpendicular. Water predominantly enters the hydrospire through the aboralmost pores, travels through the hydrospire fold at a reduced velocity, and then exists the hydrospire through the adoral-most hydrospire pores (Fig. 5.1). Very little water exits the spiracle. Water actually enters the hydrospire through the spiracle as a result of the zone of turbulent eddying that formed downstream of the blastoid oral surface.

\section{A new model for cilia-driven active flow in blastoid hydrospires}

The results from the CFD simulations of Monoschizoblastus rofei in feeding orientation suggest that a reevaluation of active flow in blastozoan respiratory structures is necessary. Although studies as far back as Paul (1978) have suggested the possibility of cilia-driven active flow in blastozoans, the hypothesis has been difficult to evaluate because the cilia are rarely preserved in the fossil record. We concur with the hypothesis of Paul (1978) and Huynh et al. (2015) that, if present in the hydrospire, cilia would be located in the hydrospire tube.

We designed CFD simulations to test for active flow in hydrospires of Monoschizoblastus rofei using the CFD module of Solidworks with conditions as described previously with the following exceptions: (1) the hydrospire was oriented horizontally; (2) external water velocity was defined at $0.5 \mathrm{~cm} / \mathrm{s}, 2 \mathrm{~cm} / \mathrm{s}$, $5 \mathrm{~cm} / \mathrm{s}$, and $10 \mathrm{~cm} / \mathrm{s}$; (3) hydrospire pores were allowed to operate as openings under ambient environmental conditions; and (4) we defined the velocity of water exiting the spiracle with the rationale that cilia-driven flow in the hydrospire tube would pump water out of the spiracle at a given velocity. Drawing on results of our previous CFD simulations, we used a value of $0.9 \mathrm{~cm} / \mathrm{s}$ as the initial excurrent velocity of water exiting the spiracle. In CFD simulations with an external current velocity of $0.5 \mathrm{~cm} / \mathrm{s}$ (Fig. 5.2), and $2.0 \mathrm{~cm} / \mathrm{s}$ (Fig. 5.3) with spiracular exit velocity of $0.9 \mathrm{~cm} / \mathrm{sec}$, the fundamental water flow through the hydrospire is analogous to that modeled in passive flow (compare to Fig. 3.4) even though the orientation of the hydrospire has rotated $90^{\circ}$ and the incurrent pore velocity has changed.

When water flow was simulated with an external current velocity of $5 \mathrm{~cm} / \mathrm{s}$ and spiracular exit velocity of $0.9 \mathrm{~cm} / \mathrm{s}$, the pattern of water flow through the hydrospire was abnormal and similar to that seen in Figure 5.1. Even with the assumption of active cilia-driven flow, the exit velocity of water leaving the spiracle was too low (relative to the current velocity) to maintain water flow through the hydrospire optimized for gas exchange. The hydrospire suffered significant respiratory leakage (adoral flow in the hydrospire fold) and reduced flow of water exiting the spiracle (Fig. 5.4).

This result suggested that an optimized ratio between external current velocity and the exit velocity of water leaving the spiracle exists for proper respiratory function in the hydrospire. We reran the CFD simulation with an external current velocity of $5 \mathrm{~cm} / \mathrm{s}$ and spiracular exit velocity of $2.5 \mathrm{~cm} / \mathrm{s}$ (Fig. 5.5 ). 

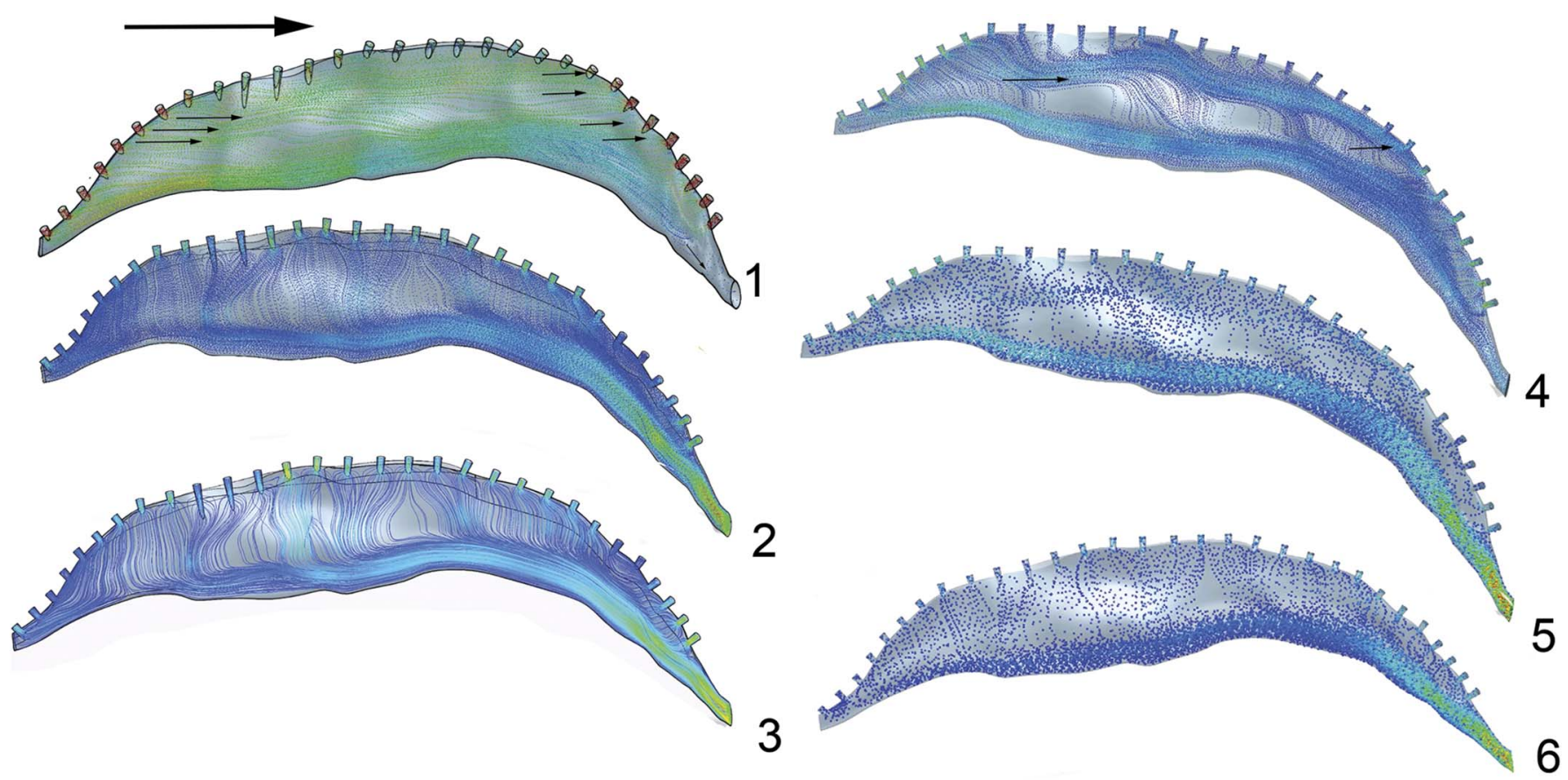

Figure 5. CFD simulations of a hydrospire of Monoschizoblastus rofei. (1) Hydrospire modeled in passive flow mode with external current velocity of $10 \mathrm{~cm} / \mathrm{s}$. Arrows illustrate water entering the hydrospires through the aboral hydrospire pores and largely exiting through the adoral pores. Minimal water volume exits the spiracle. (2) Hydrospire modeled in active flow mode with external current velocity of $0.5 \mathrm{~cm} / \mathrm{s}$ and spiracular exit velocity of $0.9 \mathrm{~cm} / \mathrm{s}$. Although the orientation of the hydrospire has rotated $90^{\circ}$, the fundamental water flow through the hydrospire is the same (compare to Fig. 3.4). (3) Hydrospire modeled in active flow mode with external current velocity of $2.0 \mathrm{~cm} / \mathrm{s}$ and spiracular exit velocity of $0.9 \mathrm{~cm} / \mathrm{s}$. Although the orientation of the hydrospire has rotated $90^{\circ}$, the fundamental water flow through the hydrospire is the same (compare to Fig. 3.4). (4) Hydrospire modeled in active flow mode with external current velocity of $5 \mathrm{~cm} / \mathrm{s}$ and spiracular exit velocity of $0.9 \mathrm{~cm} / \mathrm{s}$. The exit velocity of water at the spiracle is too low to maintain optimal water flow through the hydrospire, which suffers reduced flow out the spiracle and significant respiratory leakage. (5) Hydrospire modeled in active flow mode with external current velocity of $5 \mathrm{~cm} / \mathrm{s}$ and spiracular exit velocity of $2.5 \mathrm{~cm} / \mathrm{s}$. Under these conditions, the hydrospire achieved optimal flow within the hydrospire in contrast to the same hydrospire under passive flow conditions shown in Figure 5.1. (6) Hydrospire modeled in active flow mode with external current velocity of $10 \mathrm{~cm} / \mathrm{s}$ and spiracular exit velocity of $5 \mathrm{~cm} / \mathrm{s}$. Under these conditions, the hydrospire achieved optimal flow within the hydrospire in contrast to the same hydrospire under passive flow conditions shown in Figure 5.1.

In this simulation, the water flow through the hydrospire was optimized for efficient gas exchange. Finally, we ran a CFD simulation with an external current velocity of $10 \mathrm{~cm} / \mathrm{s}$ and spiracular exit velocity of $5 \mathrm{~cm} / \mathrm{s}$ (Fig. 5.6). In this simulation, water flow through the hydrospire was optimized for efficient gas exchange (compare to Fig. 5.1).

\section{Discussion}

CFD simulations of blastoids living in currents ranging from $>0.5 \mathrm{~cm} / \mathrm{s}$ to $10 \mathrm{~cm} / \mathrm{s}$ indicate that a velocity of water leaving the spiracle $\sim 50 \%$ of the external current velocity produces water flow through the hydrospire that is more or less optimal for gas exchange. Our CFD simulations indicate that passive water flow through the hydrospire only produces optimal flow through hydrospires at very low current velocities $(<0.5 \mathrm{~cm} / \mathrm{s})$. Therefore, we hypothesize that active cilia-driven flow through blastoid hydrospires is necessary to maintain effective respiration at the range of current velocities $(>0.5 \mathrm{~cm} / \mathrm{s}$ to $10 \mathrm{~cm} / \mathrm{s})$ in which a majority of blastoids likely lived. Blastoids likely lived in environments with fluctuating, and likely dynamically fluctuating, current velocities (according to the range of sedimentary regimes in which blastoids are found), suggesting that a system of active maintenance of water flow through the hydrospire was necessary for optimal gas exchange.
Although our CFD simulations support a hypothesis of active cilia-driven flow through blastoid hydrospires, many questions remain that will drive our research into the future. The pattern of water flow through the hydrospires and relative change in water velocity in the system are sufficient to develop the hypothesis of active cilia-driven flow in blastoid hydrospires, but the results should be quantified to provide more precise hypotheses of hydrospire function. Blastoid hydrospires come in many configurations. We have modeled the simplest configuration of hydrospires, but an obvious next step is to conduct similar analyses on more complicated hydrospire morphologies. Although time consuming and tedious, such studies are required to test the validity of our hypothesis. Given the morphological disparity seen in blastoid hydrospires, there is no a priori reason to believe they all were optimized for the same range of current velocities. Indeed, Dynowski et al. (2016) have demonstrated that fossil crinoids can adopt a range of feeding modalities to adapt to dynamic current conditions. Modern crinoids can reorient themselves dynamically (Waters, personal observations) in response to change in current velocity and direction and we assume blastoids had similar capabilities even if we do not have a biomechanical understanding of the mechanisms involved. Some blastoids were bottom dwellers and likely had different optimal conditions for respiratory function from those described here. 
Spiracles also have a complex cover-plate system that could be used to regulate the diameter of the exit pore and, therefore, hydrospire excurrent velocity so that the blastoid could dynamically adjust to changing ambient conditions. In the future, we can use more refined CFD simulations to gauge how sensitive the hydrospires are to current fluctuations and how much control blastoids had to adjust to those changes. The combination of accurate 3D models and CFD simulation software gives us the toolkit to address these and other equally compelling questions in blastoid research.

\section{Summary}

Virtual reconstructions of blastoid hydrospires from acetate peels and CFD studies of the models confirm the basic hypothesis of water flow through blastoid hydrospires from Schmidtling and Marshall (2010). Water entered hydrospires through the hydrospire pores and canals, traveled through the hydrospire fold with significantly reduced velocity allowing gas exchange, and then exited the system through the hydrospire canal and spiracle. Our reconstructions orient blastoid hydrospires horizontally as part of a living blastoid in feeding position in currents $>0.5 \mathrm{~cm} / \mathrm{s}$ rather than vertically as in previous studies. Therefore, the concept of an "average" velocity of water entering the hydrospire pore is problematic because the system is much more dynamic than previously modeled.

From our CFD simulations, we hypothesize that water flow through blastoids was cilia-driven active flow rather than passive flow. For Monoschizoblasus rofei, an exit velocity from the spiracle of approximately one-half external current velocity produced an internal water flow through the hydrospires that optimized respiration.

Our results indicate that the respiratory systems in blastoids are significantly more complex than previously thought. We have modeled a single condition in spiraculate blastoids: individual hydrospires emptying into individual spiracles with the exception of the anal interray hydrospires. Many other configurations exist in spiraculate blastoids, and each will require similar analysis to understand the flow parameters needed to produce optimal flow through the system for respiration. Fissiculate blastoids have hydrospire systems that are fundamentally different from those of spiraculate blastoids and that will require extensive study to fully understand. The possibility that fissiculate blastoids employed cilia-driven active movement of water through the hydrospires seems likely. The results lend support to the concept that hydrospires should play an increased role in providing characters for phylogenetic analysis of blastoid evolution.

\section{Acknowledgments}

We thank the reviewers for their thoughtful comments, which significantly improved the manuscript. We thank I.A. Rahman for introducing us to virtual paleontology and allowing us to participate in his projects to image echinoderms at the Swiss Light Source. B.K. Nguyen expresses her gratitude to I.A. Rahman for his encouragement and advice on the process of segmentation and visualization using SPIERS. Funding for this research came from ROA grants to Appalachian State University from NSF DEB 1036260, Assembling the Echinoderm Tree of
Life, through the University of Tennessee, and funds from the Appalachian State University Foundation. Waters received a Temminck Fellowship at the Naturalis Museum to digitize the acetate peels of blastoids.

\section{References}

Abel, R.L., Laurine, C.R., and Richter, M., 2012, A palaeobiologist's guide to micro-CT preparation: Palaeontologia Electronica, v. 15, 17 p.

Bauer, J.E., Sumrall, C.D., and Waters, J.A., 2015, Classifying blastoids through hydrospire morphology, in Zamora, S., and Rábano, I., eds., Progress in Echinoderm Palaeobiology: Cuadernos del Museo Geominero, 19: Instituto Geológico y Minero de España, Madrid, p. 33-36.

Bauer, J.E., Sumrall, C.D., and Waters, J.A., 2017, Hydrospire morphology and implications for blastoid phylogeny. Journal of Paleontology, doi: https:// doi.org/10.1017/jpa.2017.2.

Beaver, H.H., 1996, Hydrospire meshwork of the Carboniferous blastoid Pentremites Say: Journal of Paleontology, v. 70, p. 333-335.

Beaver, H.H., Fay, R.O., Macurda, D.B., Moore, R.C., and Wanner, J., 1967, Blastoids, in Moore, R.C., ed., Treatise on Invertebrate Paleontology, Part S, Echinodermata 1, v. 2: Meriden, Connecticut, New York, New York, and Lawrence, Kansas, Geological Society of America and University of Kansas Press, p. S297-S455.

Breimer, A., and Macurda, D.B., Jr., 1972, The phylogeny of the fissiculate blastoids: Verhandelingen der Koninklijke Nederlandse Akademie van Wetenschappen, Afdeling Natuurkunde, Eerste Reeks, v. 26, p. 1-390.

Breimer, A., and van Egmond, H.A., 1968, A new development of the acetate peel technique for use on fossil echinoderms: Proceedings Koninklijke Nederlandse Akademie van Wetenschappen (Series B), v. 71, p. $144-149$.

Brett, C.E., Moffat, H.A., and Taylor, W.L., 1997, Echinoderm taphonomy, taphofacies and lagerstätten, in Waters, J.A., and Maples, C.G., eds., Geobiology of Echinoderms: Paleontological Papers v. 3, p. 147-190.

Copper, P., 1967, Pedicle morphology in Devonian atrypid brachiopods: Journal of Paleontology, v. 41, p. 1166-1175.

Cunningham, J.A., Rahman, I.A., Lautenschlager, S., Rayfield, J., and Donoghue, P.C.J., 2014, A virtual world of paleontology: Trends in Ecology and Evolution, v. 29, p. 347-357.

DeFrance, J.M.L., 1819, Dictionnaire des Sciences Naturelles: v. 14, EA-EQE, p. 467.

Dexter, T.A., Sumrall, C.D., and McKinney, M.L., 2009, Allometric strategies for increasing respiratory surface area in the Mississippian blastoid Pentremites: Lethaia, v. 42, p. 127-137.

Dynowski, J.F., 2014, Hydrodynamic analysis of suspension feeding in recent and fossil crinoids: Dissertation der Mathematisch-Naturwissenschaftlichen Fakultät der Eberhard Karls Universität Tübingen zur Erlangung des Grades eines Doktors der Naturwissenschaften, http://dx.doi.org/10.15496/ publikation-1770.

Dynowski, J.F., Nebeksick, J.H., Klein, A., and Roth-Nebelsick, A., 2016, Computational fluid dynamics analysis of the fossil crinoid Encrinus liliiformis (Echinodermata: Crinoidea): PLoS ONE, v. 11, e0156408, doi: 10.1371/journal.pone.0156408.

Etheridge, R., and Carpenter, P.H., 1886, Catalogue of the Blastoidea in the Geological Department of the British Museum (Natural History): With an Account of the Morphology and Systematic Position of the Group, and a Revision of the Genera and Species (Illustrated by 20 Lithographic Plates, $\& c$.$) : Order of the Trustees.$

Fay, R.O., 1967, Phylogeny and evolution, in Moore, R.C., ed., Treatise on Invertebrate Paleontology, Part S, Echinodermata 1, v. 2: Meriden, Connecticut, New York, New York, and Lawrence, Kansas, Geological Society of America and University of Kansas Press, p. S392-S396.

Hambach, G., 1903, A revision of the Blastoideae: Transactions of the Academy of Science of St. Louis, v. 13, p. 1-67.

Huynh, T.L., Evangelista, D., and Marshall, C.R., 2015, Visualizing the fluid flow through the complex skeletonized respiratory structures of a blastoid echinoderm: Palaeontologica Electronica, Article 18.1.14A, p. $1-17$.

Jarvik, E., 1954, On the visceral skeleton in Eusthenopteron with a discussion of the parasphenoid and palatoquadrate in fishes: Kungl, Svenska Vetenskakad, Handl, v. 5, p. 1-104.

Jefferies, R.P.S., and Lewis, D.N., 1973, The English Silurian fossil Placocystites forbesianus and the ancestry of the vertebrates: Philosophical Transactions of the Royal Society, Series B, v. 282, p. 205-323.

Kammer, T.W., Sumrall, C.D., Ausich, W.I., Deline, B., and Zamora, S., 2014 Oral region homologies in Paleozoic crinoids and other plesiomorphic pentaradial echinoderms: PLoS ONE, v. 8, e77989. 
Lamarck, J.B.P.A.de M.de, 1801, Système des Animaux sans Vertèbres: Paris, Lamarck.

Muir-Wood, H.M., 1934, On the internal structure of some Mesozoic Brachiopoda: Philosophical Transactions of the Royal Society of London, Series B, v. 223 , p. $511-567$.

Nguyen, B.K., Waters, J.A., and Sumrall, C.D., 2015, Hydrodynamic modeling of brachiolar filtration systems in blastoids (Echinodermata): Geological Society of America, Abstracts with Programs, v. 47, p. 855.

Paul, C.R.C., 1978, Respiration rates in primitive (fossil) echinoderms: Thalassia Jugoslavica, v. 12, p. 277-286.

Posenato, R., 1998, The Gen. Comelicania Frech, 1901 (Brachiopoda) from the southern Alps: Morphology and Classification: Revista Italiana di Paleontologia e Stratigrafia, v. 104, p. 43-68.

Rahman, I.A., Stewart, S.E., and Zamora, S., 2015a, The youngest ctenocystoids from the Upper Ordovician of the United Kingdom and the evolution of the bilateral body plan in echinoderms: Acta Palaeontologica Polonica, v. 60, p. $39-48$.

Rahman, I.A., Waters, J.A., Sumrall, C.D., and Astolfo, A., 2015b, Early postmetamorphic, Carboniferous blastoid reveals the evolution and development of the digestive system in echinoderms: Biological Letters, v. 11, 20150776, http://dx.doi.org/10.1098/rsbl.2015.0776.

Schemm-Gregory, M., 2014, A new Givetian athyridid species from northwest Africa discovered by three-dimensional reconstruction of shell morphology of internal molds: Journal of Paleontology, v. 88, p. 708-718.

Schmidtling, R.C., II, and Marshall, C.R., 2010, Three dimensional structure and fluid flow through the hydrospires of the blastoid echinoderm, Pentremites rusticus: Journal of Paleontology, v. 84, p. 109-117.

Sollas, W.J., 1904, A method for the investigation of fossils by serial sections: Philosophical Transactions of the Royal Society, Series B, v. 196, p. 257-263.

Sprinkle, J., and Guensburg, T.E., 2004, Crinozoan, blastozoan, echinozoan, asterozoan, and homalozoan echinoderms, in Webby, B.D., Paris, F.,
Droser, M.L., and Percival, I.G., eds., The Great Ordovician Biodiversification Event: New York, Columbia University Press, p. 266-290.

Stensio, E.A., 1927, The Downtonian and Devonian vertebrates of Spitzbergen: Skrifter om Svalbard og Nordishavet, v. 12, 391 p.

Stewart, W.N., and Taylor, T.N., 1965, The peel technique, in Kummel, B., and Raup, D., eds., Handbook of Paleontological Techniques: San Francisco, W.H. Freeman, p. 224-232.

Sumrall, C.D., 2010, A model for elemental homology for the peristome and ambulacra in blastozoan echinoderms, in Harris, L.G., Böttger, S.A., Walker, C.W., and Lesser, M.P., eds., Echinoderms: Durham: London, CRC Press, p. 269-276.

Sumrall, C.D., and Waters, J.A., 2012, Universal elemental homology in glyptocystitoids, hemicosmitoids, coronoids and blastoids: Steps toward echinoderm phylogenetic reconstruction in derived blastozoa: Journal of Paleontology, v. 86, p. 956-972.

Sutton, M., Rahman, I.A., and Garwood, R., 2013, Techniques for Virtual Palaeontology: Chichester, UK, John Wiley and Sons, 208 p.

Wang, G.X., 2013, A new technique for making serial sections of solitary rugose corals: Palaeoworld, v. 22, p. 68-71.

Waters, J.A., and Horowitz, A.S., 1993, Ordinal-level evolution in the Blastoidea: Lethaia, v. 26, p. 207-213.

Waters, J.A., Sumrall, C.D., White, L.E., and Nguyen, B.K., 2015, Advancing phylogenetic inference in the Blastoidea (Echinodermata): Virtual 3D reconstructions of the internal anatomy, in Zamora, S., and Rábano, I., eds., Progress in Echinoderm Palaeobiology: Cuadrnos del Museo Geominero, 19: Instituto Geológico y Minero de España, Madrid, p. 193-197.

Accepted 26 January 2017 